\title{
Social Network Structure and Combating Social Disconnection: Implications for
}

\section{Physical Health}

\author{
Allison K. Farrell ${ }^{1}$, Sarah C. E. Stanton², \& Emma M. Marshall ${ }^{3}$ \\ 1Department of Psychology, Miami University \\ ${ }^{2}$ Department of Psychology, University of Edinburgh \\ ${ }^{3}$ School of Psychology, Deakin University
}

\begin{abstract}
Author Note
Allison K. Farrell (iD https://orcid.org/0000-0002-8233-4076

Sarah C. E. Stanton (iD https://orcid.org/0000-0002-3562-4644

Emma M. Marshall (iD https://orcid.org/0000-0002-0602-9272
\end{abstract}

The authors declare no conflicts of interest with respect to the authorship or the publication of this article.

Direct correspondence to Allison K. Farrell, Miami University, Department of Psychology, 90 North Patterson Ave, Oxford, OH 45056, United States. Email: farrelak@miamioh.edu 


\begin{abstract}
Disconnection from one's social network has detrimental links to physical health outcomes, and there has been increased interest in treating social disconnection as a public health issue. Two perspectives guide much of the research on social networks, social disconnection, and physical health. One perspective emphasizes the quality of social ties over the quantity of social ties, whereas the other emphasizes quantity over quality. In this article, we discuss the importance of combining these perspectives to promote forming networks consisting of a few close relationships in addition to some peripheral ties to effectively combat social disconnection and maintain and promote better health. We also highlight important avenues for future research, including identifying critical moderators (e.g., age, culture) and using social network interventions to address issues of causality.
\end{abstract}

Keywords: social networks, social disconnection, physical health, social relationships 


\section{Highlights}

- Close ties combat disconnection by providing responsive support and aiding growth.

- Weak ties combat disconnection by increasing and diversifying available resources.

- Sustaining both close and weak ties maintains support, self-esteem, and activity.

- More work on social network interventions and moderators of effects is needed. 


\section{Social Network Structure and Combating Social Disconnection: Implications for \\ Physical Health}

Decades of research have revealed that the quantity and quality of our social ties are closely linked to physical health, leading social (dis)connection to be advanced as a public health priority [1-2]. Social disconnection is a broad term encompassing several experiences, including loneliness; isolation or separation; loss; rejection, exclusion, or ostracism; and feeling detached or disconnected from others [3-4*]. Scholars have investigated the role of social network structure in combating social disconnection and potentially improving physical health [5]. However, a question currently unanswered in the literature is what type of social network structure would be most advantageous. In this article, we review two seemingly contradictory perspectives on how to structure social networks to combat social disconnection and promote better health, synthesizing the two perspectives together. We then discuss domains where further research is needed for researchers to capitalize on the potential for social network structure to promote and maintain good health.

\section{Quality over Quantity: Benefits of Close Ties}

One major body of literature suggests that people should prioritize having a few high-quality close relationships over having a greater number of superficial social ties. It is normative for adults_especially older adults—to "prune" their social networks, building smaller and closer networks $\left[6,7^{* *}, 8\right]$. People do this by dropping peripheral, superficial social ties which take more effort to maintain [9-10]. Pruning results in greater life satisfaction and positive emotional experiences without loss of emotional support $\left[6,7^{* *}, 8\right]$, and engagement with close social ties (rather than peripheral ties) predicts better pulmonary functioning [11] and lower mortality risk [12]. 
Close relationships fulfil broad connectedness needs efficiently because close others are more likely to be attachment figures who provide two key health-relevant functions. First, they provide a safe haven from stressful experiences. People are more likely to turn to close (vs. weak) ties for support in times of stress [13*]. Close others are better equipped to provide more responsive support (i.e., support characterized by caring, understanding, and validation) than weaker ties [14]. It is this responsive support (or lack thereof) which is most closely tied to physical health [15-16]. Second, attachment figures serve as a secure base for exploration and growth. Close ties facilitate goal pursuit [17], including health-relevant goals like exercise [18-19]. Furthermore, close ties help us grow (e.g., toward an ideal version of the self [20]) and beliefs that a relationship will provide future self-expansion opportunities predict better ratings of physical health via greater positive affect [21].

Individuals must be careful not to prune their social networks too severely, however, as there are risks associated with overly small social networks. Not all close relationships are positive; in fact, the most common ambivalent social ties (i.e., those involving highly positive and highly negative perceptions and behaviors) are close family members [22]. Having more ambivalent ties in a social network predicts heightened cardiovascular disease risk and markers of aging like shortened telomere length [23]. Furthermore, relying solely on a few social ties for all connectedness needs may overwhelm those relationships, especially in times of high stress or socioeconomic disadvantage [24]. In contrast, turning to different close others for different forms of connectedness (e.g., soothing anxiety, celebrating successes) is associated with better well-being than relying on just a few people for all needs [25]. This suggests network diversity may have similar effects on health. Finally, if a network has only a few close 
ties, the loss of a single network member to death [26] or divorce [27] may decimate connectedness and lead to severe impacts on physical health.

\section{Quantity over Quality: Benefits of Large Networks}

Although close relationships are a critically important feature of social networks that contribute to physical health, a competing body of literature suggests that it is better for health to have a larger, more diverse social network containing many weaker or peripheral ties. Larger networks and more frequent interactions with diverse others are associated with better immune, cognitive, and physical functioning [28-29] and lower heart disease risk [30].

This perspective argues that the amount and diversity of social resources obtained from a large social network have important health benefits. When faced with new or unusual problems (e.g., receiving a new diagnosis for Type II diabetes), having a larger network made up of individuals with diverse experiences increases the chances of having someone with similar experiences who can provide information or empathy (e.g., sympathizing about pain from testing glucose levels, suggesting different testing methods to reduce pain [31]). Large social networks can also maintain self-esteem by reassuring individuals of their social value, and higher self-esteem is associated with better health outcomes. In a longitudinal study, Stinson and colleagues [32] showed that having fewer friends predicted drops in self-esteem, which in turn predicted having more health problems. Furthermore, maintaining peripheral relationships encourages individuals to engage in activities that improve cognitive and physical functioning, such as exercise classes or volunteer work [33]. Unlike many marital or family relationships, individuals need to leave the house to interact with peripheral social ties, guaranteeing a basic level of physical activity (34**). Finally, having a larger network ensures for easier transitions when close ties are lost or dropped, as it provides an accessible pool 
of social ties that might be strengthened to take the place of lost or negative relationships.

As with the "less is more" social network perspective, there are caveats to the benefits of a large social network with many weaker ties. As mentioned above, weaker social ties are effortful to maintain [10] and may be less rewarding. Weaker social ties can promote social snacking, interactions that encourage superficial levels of selfdisclosure and responsiveness but do not provide the full range and depth of benefits obtained from interactions with closer ties [35-36]. Furthermore, despite a larger number of ties in a network, it is less common for people to seek support from weak ties, hindering necessary support transactions and their health impact [13*].

\section{Combining the Quality and Quantity Perspectives}

Although these two perspectives on social network structure and physical health may appear contradictory to one another, their mechanisms and caveats have meaningful overlap (see Table 1). It seems that the most adaptive social network for combating disconnection and maintaining and improving physical health consists of a mix of a few close ties and a reasonably-sized-and not too diffuse-collection of weaker, peripheral ties. This structure allows for highly responsive support and personal growth through attachment bonds, but also provides a more diverse network to encourage engagement in a broader array of health-promoting activities. Furthermore, it provides a larger group of people to turn to if close relationships are overwhelmed, unequipped to help with a particular issue, or dissolved.

Combined, these perspectives suggest that close and weak ties operate in complementary ways and improve health through three major channels: Social support, self-esteem, and activity engagement. Close ties are our primary sources of social support [13*], but weaker ties can provide specialized support in unique or unusual 
circumstances [31]. Close ties provide opportunities for personal growth [20], while a large number weaker ties make us feel like a desired social partner with high relational value [32]. Both of those processes enhance self-esteem. Finally, both close and weaker ties can promote engagement in activities that fulfil health-relevant goals and improve or maintain physical health $[17,33]$.

One of the first studies comparing the effects of close and peripheral social ties on health revealed evidence for this complementary pattern. Interacting with close ties promoted greater positive mood, whereas interacting with peripheral ties promoted greater physical activity [34**]. Thus, when trying to reduce social disconnection to promote better health, researchers should not target social tie quantity or quality in isolation, but instead ensure individuals have enough of both represented in their social networks.

\section{Future Research Directions}

Future research should consider moderators of these effects. Larger, more diffuse social networks are normative in adolescence and early adulthood (i.e., through the twenties [8]). Some studies with these age groups have shown that social interaction quantity is more predictive of health than the quality, but effects of quality strengthen once individuals enter their thirties [37-38*]. Although social tie quality is still linked to health in adolescence [39], quantity might be especially important in this age group. There are likely cultural differences in the effects of network structure on health as well; for example, Hispanic individuals show similar levels of support to NonHispanic White individuals, but they report valuing this support more, suggesting they may receive more benefits from it [40*]. Furthermore, individuals facing unique health challenges might benefit from a larger social network that can cater to their more specialized support and activity needs. It is also possible that people with greater 
support needs (e.g., due to illness) would benefit from a larger social network to ease the caregiving responsibilities that typically fall on and strain their close relationships partners [41].

Within the broad category of close ties, it is unclear whether different types of close relationships (e.g., family, friends, romantic partners) have distinct effects on connectedness and physical health. Early research in this area suggested that it would be difficult to overcome the negative impacts of a low-quality romantic relationship through other social ties [42-43], but recent research suggests that family relationships may be more impactful on health than romantic relationships [44]. Beyond quality and quantity of close ties, scholars should collect information about the types of close ties involved in individuals' social networks to determine if specific relationships have unique or stronger effects.

The health effects of social ties may also depend on the health behaviors enacted by those ties. Social influence and social contagion can have health-promoting or healthundermining effects depending on the beliefs of social network members [45-48]. If our social ties make engaging in health-promoting behaviors seem normative, give us faith that we can control our health-relevant behavior, and directly encourage us to pursue good health, then we are likely to see positive effects. In contrast, when poor health or risky health behaviors are normative in our network and we are pressured to maintain unhealthy habits, social networks may do more harm than good [45-48].

The quality and quantity of social ties are not the only network features worthy of investigation. Network analysis allows for several additional network features to be studied, including network density (i.e., the extent to which contacts are linked directly or indirectly) and centralization (i.e., the extent to which the network is reliant on a few contacts to stay connected) [47]. These types of metrics are related to a wide range of 
physical and mental health outcomes [47] and should be considered when trying to identify the most efficacious network structure for health.

Finally, a particularly fruitful avenue for future research involves investigating social network interventions. Interventions improving people's social network ties and interactions have shown promise for various health behaviour outcomes (e.g., sexual health, HbA1c, alcohol misuse, and smoking [48]). However, much of the research on social networks and health is correlational, making it difficult to determine the causal direction of these links [5, 49]. For example, poor health can make it difficult to engage in activities that help form and maintain relationships [34**], and third variables like neuroticism can undermine both social networks and health [49-50]. Intervention research can establish causality and help identify the most efficient and effective ways to improve connectedness and health. Interventions could also address questions regarding the ideal number of close and peripheral ties, which have been addressed vaguely in the literature thus far.

Social disconnection is a major threat to physical health. However, it can be mitigated with a carefully constructed social network. Extant literature points to the complementary benefits of a few close relationships in addition to some peripheral ties to provide opportunities for support, self-esteem, and activity engagement. Intervention studies and future research testing moderators of these effects are needed to clarify how researchers may maximize the beneficial effects of social network structure for physical health outcomes. 


\section{References}

1. Holt-Lunstad J, Robles TF, \& Sbarra, DA: Advancing social connection as a public health priority in the United States. Am Psychol 2017, 72: 517.

2. Jaremka LM, Sunami N: Threats to belonging threaten health: Policy implications for improving physical well-being. Policy Insights Behav Brain Sci 2018: 5, 90-97.

3. Holt-Lunstad J. Why social relationships are important for physical health: A systems approach to understanding and modifying risk and protection. Ann Rev Psychol 2018, 69: 437-458.

4. *Pietromonaco PR, Collins NL. Interpersonal mechanisms linking close relationships to health. Am Psychol 2017, 72: 531-542.

An excellent review of how close ties fulfil attachment functions and the implications of these processes for physical health.

5. Cohen S, Janicki-Deverts D: Can we improve our physical health by altering our social networks? Perspect Psychol Sci, 2009, 4: 375-378.

6. Huxhold O, Fiori KL, Windsor TD: The dynamic interplay of social network characteristics, subjective well-being, and health: The costs and benefits of socio-emotional selectivity. Psychol Aging, 2013, 28: 3-16.

7. ${ }^{* *}$ Rook KS, Charles ST. Close social ties and health in later life: Strengths and vulnerabilities. Am Psychol 2017, 72: 567-577.

A thorough review of the quality over quantity perspective on the benefits of fewer, closer ties for health and well-being

8. Wrzus C, Hänel M, Wagner J, \& Neyer FJ: Social network changes and life events across the life span: a meta-analysis. Psychol Bull 2013, 139: 53-80. 
9. English T, Carstensen LL: Does positivity operate when the stakes are high? Health status and decision making among older adults. Psychol Aging 2015, 30: 348-355.

10. Lang FR, Wagner J, Wrzus C, Neyer FJ: Personal effort in social relationships across adulthood. Psychol Aging 2013, 28: 529-539.

11. Crittenden CN, Pressman SD, Cohen S, Janicki-Deverts D, Smith BW, Seeman TE: Social integration and pulmonary function in the elderly. Heal Psychol, 2014, 33: 535-543.

12. Seeman TE, Kaplan GA, Knudsen L, Cohen R, Guralnik J: Social network ties and mortality among the elderly in the Alameda County Study. Am. J. Epidemiol., 1980, 126: 714-723.

13. *Kammrath LK, Armstrong BF, Lane SP, Francis MK, Clifton M, McNab KM, Baumgarten OM: What predicts who we approach for social support? Tests of the attachment figure and strong ties hypotheses. J Pers Soc Psychol 2020, 118: 481-500.

Discusses both attachment and social network perspectives on support seeking and examines key propositions of both

14. Reis HT, Clark MS, Holmes JG: Perceived Partner Responsiveness as an Organizing Construct in the Study of Intimacy and Closeness. In Handbook of closeness and intimacy. Edited by Mashek DJ, Aron AP. Lawrence Erlbaum Associates Publishers; 2004: 201-225.

15. Selcuk E, Ong AD: Perceived partner responsiveness moderates the association between received emotional support and all-cause mortality. Heal Psychol 2013, 32: 231-235. 
16. Stanton, SCE, Slatcher RB, Reis HT: Relationships, health, and well-being: The role of responsiveness. In New directions in the psychology of close relationships. Edited by Schoebi D \& Campos B Routledge/Taylor \& Francis; 2019: $118-135$.

17. Fitzsimons GM, Finkel EJ, van Dellen MR: Transactive goal dynamics. Psychol Rev 2015, 122: 648-673.

18. Berli C, Rauers A, Lüscher J, Hohl DH, Keller J, Stadler G: Social exchange processes and their association with couples' health regulation and healthrelated outcomes. Eur Heal Psychol 2016, 18, 353.

19. Sackett-Fox K, Gere J, Updegraff J: Better together: The impact of exercising with a romantic partner. J Soc Pers Relatsh in press.

20. Cheung EO, Gardner WL: With a little help from my friends: Understanding how social networks influence the pursuit of the ideal self. Self Identity 2016, 15: 662-682.

21. Stanton SCE, Spence K, Kähkönen JE, Dobson K: Individual and dyadic associations among relational self-expansion potential, affect, and perceived health. Pers Relatsh 2020, 27: 550-570.

22. Fingerman KL, Hay EL, Birditt KS: The best of ties, the worst of ties: Close, problematic, and ambivalent social relationships. J Marriage Fam 2004, 66: 792-808.

23. Holt-Lunstad J, Uchino BN: Social ambivalence and disease (SAD): A theoretical model aimed at understanding the health implications of ambivalent relationships. Perspect Psychol Sci 2019, 14: 941-966.

24. Finkel EJ, Hui CM, Carswell KL, Larson, GM: The suffocation of marriage: Climbing Mount Maslow without enough oxygen. Psychol Inq 2014, 25: 1-41. 
25. Cheung EO, Gardner WL, Anderson JF: Emotionships: Examining people's emotion-regulation relationships and their consequences for wellbeing. Soc Psychol Pers Sci 2015, 6: 407-414.

26. Stroebe et al., this issue

27. Sbarra \& Whisman, this issue

28. Cohen S, Doyle WJ, Skoner DP, Rabin BS, \& Gwaltney JM: Social ties and susceptibility to the common cold. JAMA 1997, 277: 1940-1944.

29. Cornwell EY, Waite LJ. Social network resources and management of hypertension. J Heal Soc Behav 2012, 53: 215-231.

30. Beller J, Wagner A: Disentangling loneliness: differential effects of subjective loneliness, network quality, network size, and living alone on physical, mental, and cognitive health. J Aging Heal 2018, 30: 521-539.

31. Thoits PA. Mechanisms linking social ties and support to physical and mental health. J Heal Soc Behav 2011, 52: 145-161.

32. Stinson DA, Logel C, Zanna MP, Holmes JG, Cameron JJ, Wood JV, Spencer SJ: The cost of lower self-esteem: testing a self-and social-bonds model of health. $J$ Pers Soc Psychol 2008, 94: 412-428.

33. Cornwell B, Laumann EO: The health benefits of network growth: New evidence from a national survey of older adults. Soc Sci Med 2015, 125, 94106.

34. **Fingerman KL, Huo M, Charles ST, Umberson DJ: Variety is the spice of late life: Social integration and daily activity. J Gerontolog Ser B 2020, 75: 377388. 
One of the only studies to explicitly test and link the quality and quantity perspectives on social ties and link them to health outcomes, finding complementary effects of close and peripheral ties.

35. Sbarra DA, Briskin JL, Slatcher RB: Smartphones and close relationships: The case for an evolutionary mismatch. Perspect Psychol Sci 2019, 14: 596-618.

36. Gardner WL, Pickett CL, Knowles M: Social snacking and shielding. In The social outcast: Ostracism, social exclusion, rejection, and bullying. Edited by Forgas JP, Williams KD, von Hippel W. Taylor \& Francis; 2015.

37. Carmichael CL, Reis HT, Duberstein PR: In your 20s it's quantity, in your 30s it's quality: The prognostic value of social activity across 30 years of adulthood. Psychol Aging 2015, 30: 95-105.

38. *Zhaoyang R, Sliwinski MJ, Martire LM, Smyth JM: Social interactions and physical symptoms in daily life: quality matters for older adults, quantity matters for younger adults. Psychol Heal 2019, 34: 867-885. Makes a strong case for moderating effects of age on the effects of network quality vs. quantity on health.

39. Imami L, Stanton SCE, Zilioli S, Tobin ET, Farrell AK, Luca F, Slatcher RB: Selfdisclosure and perceived responsiveness among youth with asthma: Links to affect and anti-inflammatory gene expression. Pers Soc Psychol Bull 2019, 45: 1155-1169.

40. *Flores M, Ruiz JM, Goans C, Butler EA, Uchino BN, Hirai M ... Smith TW: Racialethnic differences in social networks and perceived support: Measurement considerations and implications for disparities research. Cult Divers Ethn Minor Psychol 2020, 26: 189-199. 
Suggests important future directions for this line of work considering race, ethnicity, and culture, and the potential of social network structure interventions to combat health disparities

41. Karantzas GC, Simpson JA: Attachment and aged care. In Attachment theory and research: New directions and emerging themes. Edited by Simpson JA, Rholes SW. Guilford Press; 2015.

42. Coyne JC, DeLongis A: Going beyond social support: the role of social relationships in adaptation. J Consult Clin Psych 1986, 54: 454-460.

43. Holt-Lunstad J, Birmingham W, Jones BQ: Is there something unique about marriage? The relative impact of marital status, relationship quality, and network social support on ambulatory blood pressure and mental health. Ann Behav Med 2008, 35: 239-244.

44. Woods SB, Priest JB, Roberson PN: Family versus intimate partners: Estimating who matters more for health in a 20-year longitudinal study. $J$ Fam Psychol 2020, 34: 247-256.

45. Howland M, Farrell AK, Simpson JA, Rothman AJ, Burns RJ, Fillo J, Wlaschin J: Relational effects on physical activity: A dyadic approach to the theory of planned behavior. Heal Psychol 2016, 35: 733-741.

46. Joyal-Desmarais K, Lenne RL, Panos ME, Huelsnitz CO, Jones RE, Auster-Gussman LA, ... Rothman AJ: Interpersonal effects of parents and adolescents on each other's health behaviours: a dyadic extension of the theory of planned behaviour. Psychol Heal 2019, 34: 569-589.

47. Smith KP \& Christakis NA: Social networks and health. Annu Rev Sociol 2008, 34: 405-429. 
48. Hunter RF, de la Haye K, Murray JM, Badham J, Valente TW, Clarke M, Kee F: Social network interventions for health behaviours and outcomes: a systematic review and meta-analysis. PLoS Med 2019, 16: e1002890.

49. Farrell AK, Stanton SCE, Sbarra DA: Good theories in need of better data: Combining Clinical and Social Psychological Approaches to Study the Mechanisms Linking Relationships and Health. Perspect Psychol Sci in press. 50. Lahey BB: Public health significance of neuroticism. Am Psychol 2009, 64: 241-256.

51. Wilson RE, Harris K, Vazire S. Personality and friendship satisfaction in daily life: Do everyday social interactions account for individual differences in friendship satisfaction?. Eur J Pers 2015, 29: 173-186. 